\title{
NOT A
}

\section{UNA CARTA DE DOÑA CAROLINA MICHAELIS}

\author{
JosÉ FRADEJAS LEBRERO
}

Uno de los tres filólogos o críticos literarios más importantes de la Literatura peninsular del siglo XX es doña Carolina Michaelis de Vasconcellos.

Cuando se crea la Gesellschaf für Romanische Literatur (1902), los tres van juntos: el socio núm. 4 es don Marcelino Menéndez Pelayo, el núm. 5 don Ramón Menéndez Pidal y el núm. 6 doña Carolina Michaelis y conste que era más vieja, pues había nacido en 1851 y aún no era doctora, lo sería en Friburgo en 1904, con una obra monumental y maestra: la edición y estudio del Cancionero de Ajuda.

Había ya colaborado en el Homenaje a Menéndez Pelayo (1899), con quien se carteaba de cuando en cuando y en 1903 proporcionó el texto más interesante de la Leyenda del abad don Juan de Montemayor a don Ramón Menéndez Pidal, quien le ruega en 1903 que:

permita ... que figure su nombre en la dedicatoria de este librito, ya que no en la portada, como debiera.

y, además, colaboró en su Homenaje en 1930.

Pues bien, esta doctísima señora - casada con el portugués Vasconcellos, residiendo muchos años en Oporto- que dominaba las literaturas peninsulares del Medievo y del Renacimiento, que fue ejemplo sin igual en su primera juventud, como buena alemana, pide consejo y auxilio para sus vocacionales estudios hispánicos a dos españoles, hijos de alemán: don Juan Eugenio Hartzenbusch y doña Cecilia Böhl de Faber. Sin duda tenía noticias de ambos, además, porque Broukhaus había editado en 1863 las Obras de Hartzenbusch prologadas por Ferrer del Río y los números 1, 3, 5, 8, 13, 16, 17, 20 y 23 de aquella Colección de Autores Españoles, iniciada en 1860, eran obras de doña Cecilia Böhl de Faber.

He aquí la carta que escribe a Hartzenbusch, la cual es todo un poema y se conserva en la Biblioteca Nacional de Madrid, entre los papeles, ms. 2087, carta núm. 522: 
Muy señor mío,

Aunque soy una desconocida para Vd. me atrevo a dirigirle la presente.

Soy una joven alemana y desde más de tres años me he dado a aprender el bello idioma español, su historia y su literatura son casi mis únicos estudios. La hermosisima comedia de Vd. Los amantes de Teruel es la primera que he letdo; y a Vd. que el primero despertó en mí un ardiente amor para todo lo que se llama español, a él le ofrezco, como a mi maestro y preceptor, un pequeño trabajo mío sobre el Cid. Sea Vd. un indulgente crítico para con mis diez y siete años.

También le envío a Vd. los primeros pliegos de una co. lección de comedias del antiguo teatro español publicada por mí con apuntes biográficos y críticos. Ya ha dos años que estoy activa en la publicación de obras modemas y antiguas españolas, hecha por el señor F. A. Brockhaus en Leipzique.

Mucho desearía escribir de cuando en cuando artículos en alguna Revista española, sea críticos, o biográficos, o artísticos; y aún más me agradaría si pudiera acaso entrar como miembro correspondiente en la junta literaria que bajo su presidio de Vd., hace poco se ha formado, y a Vd. le voy a pedir el favor de conseguir para mi tales permisiones.

Me hará Vd. aún otro favor? He escrito una cartita a la señora Cecilia de Arrom (née Böhl de Faber) y no se adónde dirigir mi carta. Acaso Vd. puede entregarla a ella misma o a su editor Mellado; con un ejemplar del Cid.

Su segura y atentísima servidora

\section{Carolina Michaëlis}

Berlín

Marienhofer 27

Berlin 9-11-68 


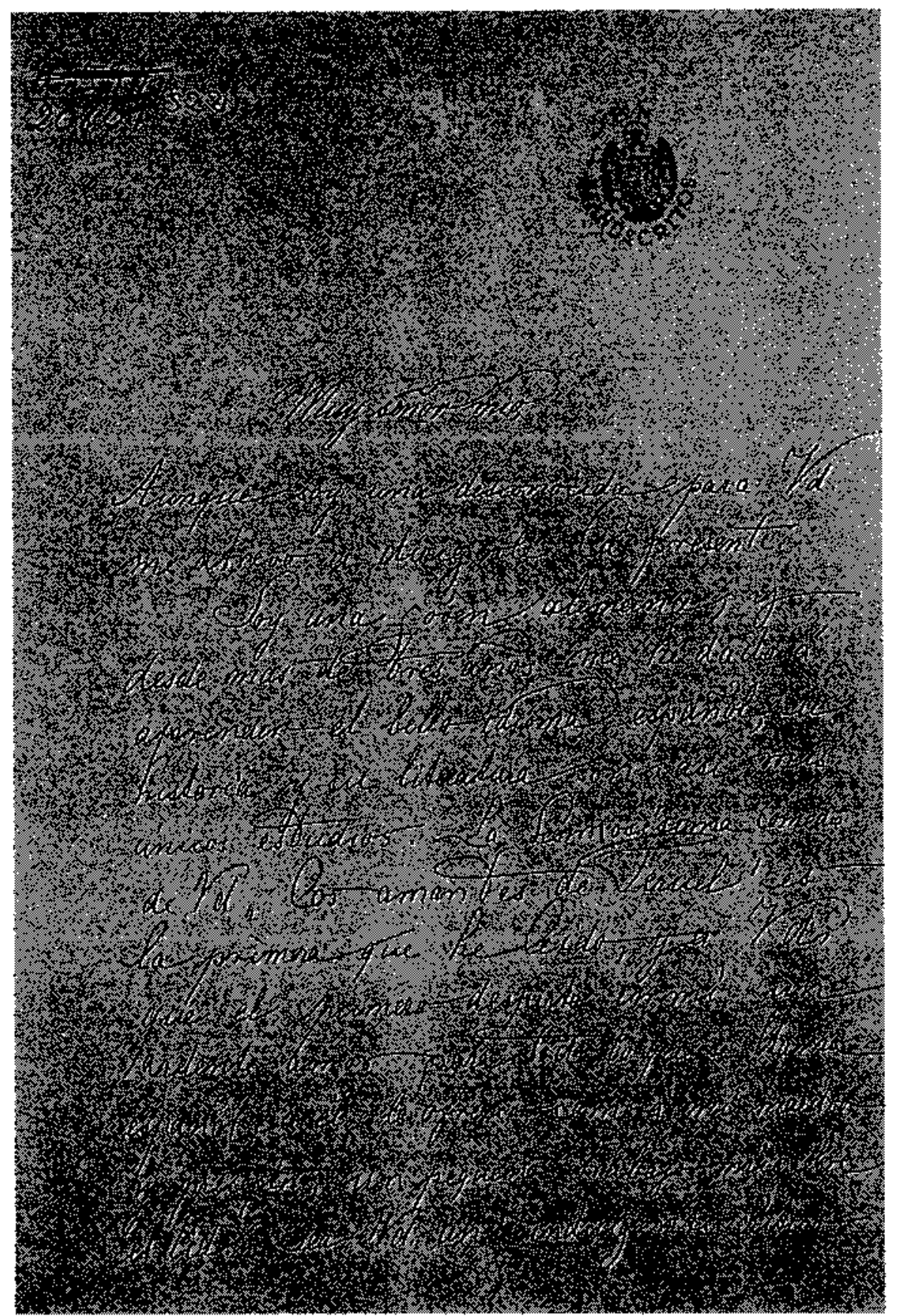




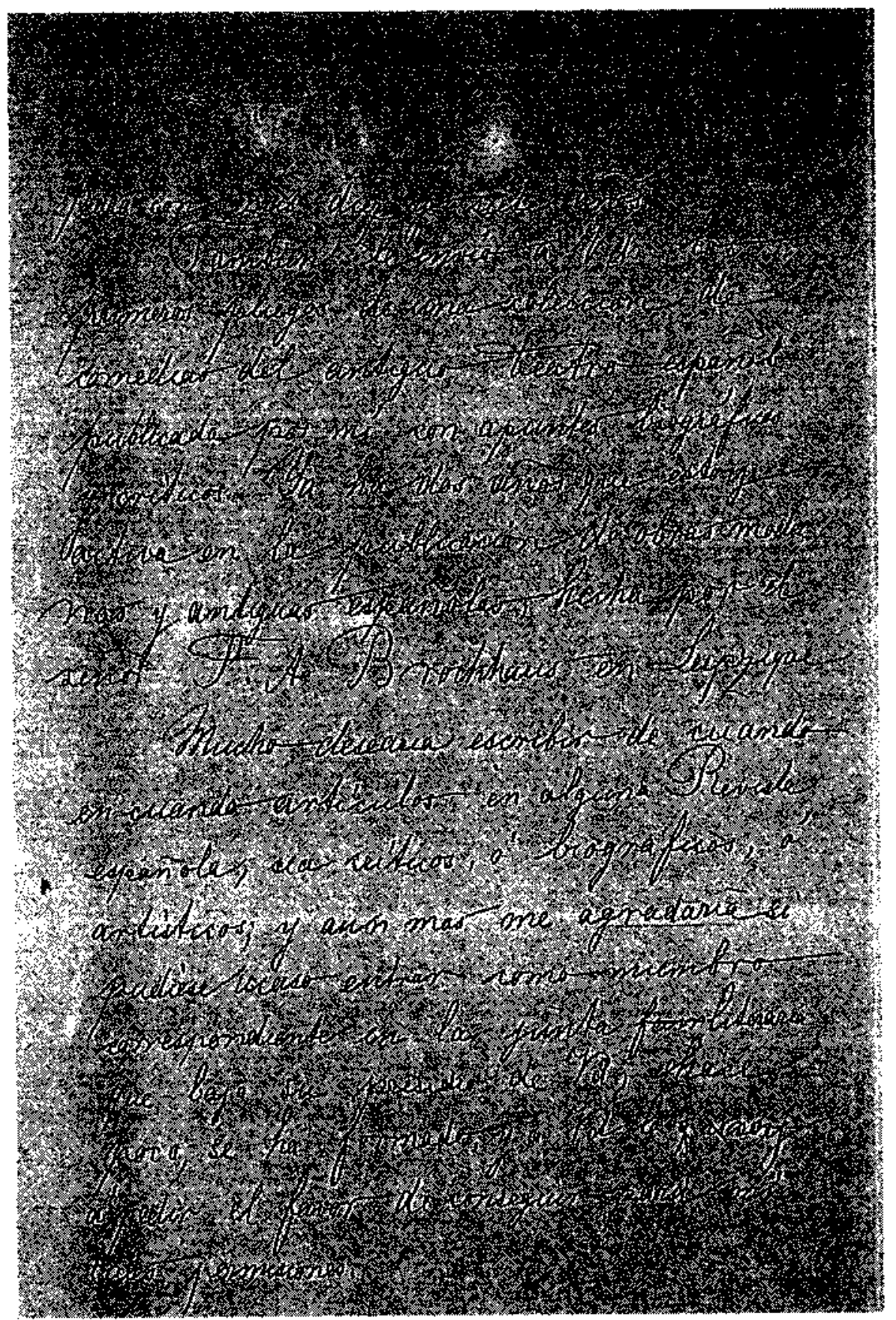




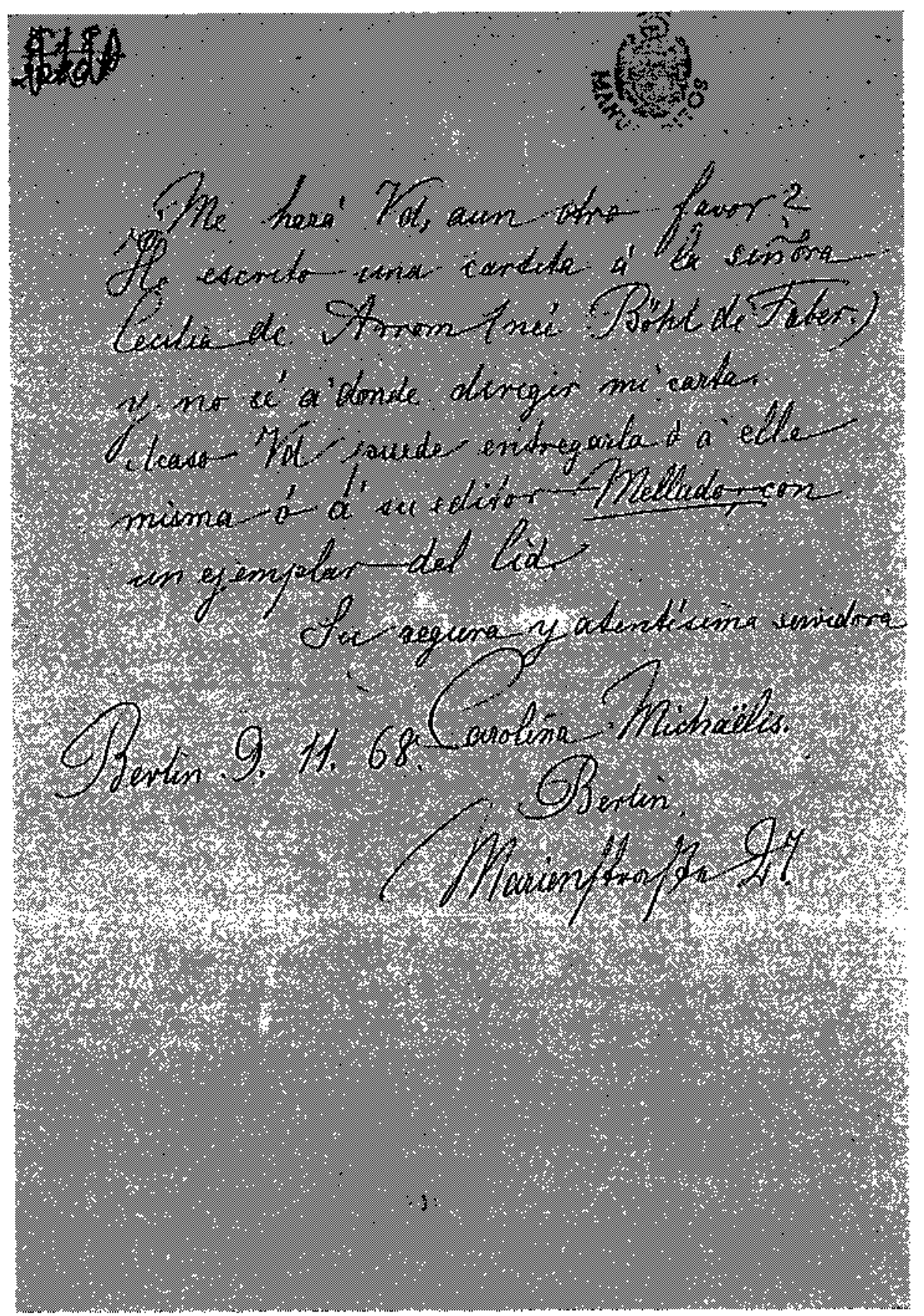


Es sorprendente el dominio del español en una jovencita de diez y siete años que lleva tres años estudiándolo y que se atreve, nada menos, a escribir los Erlaterungen zu Herder's Cid (1868) y editar comedias del Siglo de Oro. Parece que estas últimas seguramente se interrumpieron en aquel año y salieron por fin a la luz en Tres flores del teatro antiguo español, en Leipzig, 1876 (Guillén de Castro: Las mocedades del Cid; Coello: La tragedia más lastimosa de amor, Dar la vida por su dama o El Conde de Sex; y Moreto: El desdén con el desdén). Pero ya antes había publicado el Romancero del Cid, 1871 (nueva edición), en Antología Española. Primera Parte. Poetas de los siglos XV-XVII, Leipzig, Brockhaus, 1875. Es decir, no cejó, ni cejará jamás de estudiar lo español; recuérdense sus Estudios sobre o Romanceiro peninsular, Cultura Española, 1907-1909, más conocido como Os romances vellos en Portugal.

Pero la historia de esta carta no se acaba aquí pues, quince días más tarde, don Juan Eugenio respondió con prontitud a sus requerimientos, y no parece mera cortesía, pues se extiende a consejos críticos:

Madrid, 24 de noviembre de 1868

\section{Srt. ${ }^{a} D .^{a}$ Carolina Michaëlis}

Muy Sra. mía, de todo mi respeto y aprecio: Recibí a su tiempo la honrosísima carta de V.; y algunos días después los ejemplares del Cid de Herder. Envié inmediatamente a Sevilla, donde reside de ordinario la S. ${ }^{a} D .{ }^{a}$ Cecilia Böhl la carta que V. me enviaba para ella, y me ha contestado haberla recibido en el Puerto de Santa María, adonde ha ido para asistir a su hermana la Sra. D. ${ }^{a}$ Aurora Böhl, que se halla gravemente enferma. El ejemplar del Cid destinado por V. a Cecilia se lo remito hoy al Puerto.

He procurado leer sus iluminaciones y notas puestas por $V$. al Cid de Herder; y lo que he podido entender de ellas me ha parecido muy bien. Pero Carolina, lo poco que yo sabia del alemán lo he olvidado, lo he perdido después de mi última enfermedad del año pasado, la vista me ha quedado muy débil, me cuesta mucho trabajo leer el alemán en una edición compacta, y no tengo de quien valerme para que me lea lo que yo no puedo: mi hijo no sabe la lengua de V. De él me he valido para cotejar el pliego de Las mocedades del Cid, $1 .{ }^{a}$ Parte con una edición española, y hemos las faltas de imprenta que voy a notar: 
Pág. VI, verso 310:

se lee: «Esto es blandir o temblar»

debe imprimirse: «Esto, ¿es blandir o temblar?»

En la misma página, verso 405 :

se dice: Date paso. Debe decir: daré paso.

Pág. 13, verso 470:

soldat, debe decir: "soltad".

Pág. 23, verso 629:

"recibirla», debe ser: recibilla para que consuene con casilla.

Pág. 25, verso 728 :

Se lee: «Hacia el conde está». Falta la palabra mirando.

Pág. 26, verso 768:

Dice: «espejo». Debe ser «Despojos», consonante con oios.

Pag. 27, verso 812:

Dice "quienes». Debe imprimirse quiés consonante con pies.

Me he tomado la libertad de hacer a $V$. estas advertencias porque desearía que el tomo del Tesoro Español que V. imprime saliera tan bien hecho como la edición de Calderón hecha por Keil, que es la mejor que tenemos de este gran poeta.

Yo solo soy Presidente de una Sociedad de bibliofilos [Españoles] la cual no tiene individuos correspondientes.

Me felicito sobremanera de haber hecho conocimiento con una persona de tan alto mérito como Vd. A los tres años o poco más de estudio del castellano poder publicar una colección de obras dramáticas españolas con apuntes acerca de ellos es cosa sin ejemplo hasta ahora. Saludo a V. con la admiración y respeto debido a un ingenio ... y b.l.p. de V. s.s.s. 